\title{
Synthesis of hierarchical SAPO-11 for hydroisomerization reaction in refinery processes
}

\author{
Zhipeng Ma $\cdot$ Zhen Liu $\cdot$ Hao Song $\cdot$ \\ Peng Bai $\cdot$ Wei Xing $\cdot$ Zifeng Yan $\cdot$ Lianhong Zhao \\ Zhongdong Zhang $\cdot$ Xionghou Gao
}

Received: 2 May 2014/ Accepted: 23 June 2014/Published online: 14 July 2014

(C) The Author(s) 2014. This article is published with open access at Springerlink.com

\begin{abstract}
A series of SAPO-11 molecular sieves with hierarchical structure (Meso-SAPO-11) were synthesized by adding certain amount of carbon particles. The coexisting micropore and mesopore feature of Meso-SAPO11 was confirmed by $\mathrm{N}_{2}$ adsorption-desorption isotherm, TEM and SEM. XRD, TEM, SEM and Py-FTIR were employed to examine the crystallization, morphology and acidity properties of the resulting meso-SAPO-11 prepared from two typical kinds of carbon material and different contents of template. The hydroisomerization performance of meso-SAPO- 11 as catalyst support and acid active site, with loading $0.5 \mathrm{wt} \% \mathrm{Pt}$ as metal active site, was also tested to evaluate the mesoporous effects on catalytic activity and product selectivity.
\end{abstract}

Keywords SAPO-11 - Hierarchical structure $\cdot$ Hard template $\cdot$ Carbon material $\cdot$ Hydroisomerization

Z. Ma · Z. Liu $(\bowtie) \cdot$ H. Song · P. Bai · W. Xing ·

Z. Yan $(\bowtie) \cdot$ Z. Zhang

College of Chemical Engineering, State Key Laboratory of

Heavy Oil Processing, Key Laboratory of Catalysis, CNPC,

China University of Petroleum, No. 66 Changjiang West Road,

Qingdao 266580, People's Republic of China

e-mail: zhenliu@upc.edu.cn

Z. Yan

e-mail: zfyancat@upc.edu.cn

W. Xing

College of Science, China University of Petroleum, No. 66 Changjiang West Road, Qingdao 266580, People's Republic of China

L. Zhao $\cdot$ Z. Zhang $\cdot$ X. Gao

Lanzhou Petrochemical Research Center, Petrochemical

Research Institute, PetroChina Company Limited, Lanzhou

730060, People's Republic of China

\section{Introduction}

With the environmental regulations becoming more stringent and people's environmental awareness getting stronger, the demand for clean production of gasoline, diesel and lubricants and other products from crude oil is increasing. However, because of that crude oil is becoming heavier and poorer in quality, the deep upgrading and full utility of heavy oil attract extensive attention and also become more of a disposal challenge. Hydroisomerization, as a technology to produce higher quality petroleum products, is getting more and more attentions. In the production of gasoline, the octane number of the product can be improved by hydroisomerization. In the production of diesel and lubricants, the pour point and viscosity nature of the product can be ameliorated by hydroisomerization, while maintaining the efficiency of carbon conversion and yield target oil product for maximum [1]. The hydroisomerization catalyst is a kind of bifunctional catalyst, which includes both a metal and an acid active site. The acid function is usually provided by acidic support, such as amorphous oxide or oxide mixture $\left(\mathrm{Al}_{2} \mathrm{O}_{3}, \mathrm{SiO}_{2}-\mathrm{Al}_{2} \mathrm{O}_{3}\right.$, $\mathrm{ZrO}_{2} / \mathrm{SO}_{4}{ }^{2-}$ treated by HF) [2, 3], aluminosilicate molecular sieves (Y, Beta, Mordenite, ZSM-5, ZSM-22) [4-6], or silicoaluminophosphate molecular sieves (SAPO-11, SAPO-31, SAPO-41) [7-10].

SAPO-11 molecular sieve, which has one-dimensional 10-ring pore structure and suitable surface acidity, has been widely used in refinery process because of the good stability and selectivity in alkane isomerization [11-15]. However, the application of traditional SAPO-11 is restricted by its microporous structure, especially for the long-chain alkane isomerization process. The reactant conversion and isomer product selectivity are significantly reduced by low mass transfer rate. As we know, hierarchical porosity by 
generating mesopores inside microporous molecular sieve is a feasible approach to reduce the mass transfer resistance of the reactants and construct more reactive sites inside microporous molecular sieve, furthermore to improve the reactivity [16]. Therefore, SAPO-11 with hierarchical structure (meso-SAPO-11) has been attracted more and more attention $[17,18]$.

Template method is commonly used to generate mesopores inside crystallized molecular sieve $[19,20]$. The template commonly used to construct hierarchical structure is organic macromolecular surfactant, i.e. soft template strategy. However, specially designed organic macro molecular surfactant used to act as soft template is usually expensive, which restricts to be used in large scale, especially for industrial application. The account relative to soft template is hard template strategy, which uses a structural rigid organic or inorganic material as template. Normally, carbon material is a best choice as hard template for aluminosilicate or silicoaluminophosphate synthesis, which could be removed by simple thermal treatment in the presence of oxygen or air. As an example, hard template strategy has been applied to produce hierarchical structured zeolite, such as macroporous MFI zeolite crystals by applying polystyrene beads [21] as the macropore template or nanosized ZSM-5 crystals by carrying out the crystallization in the confined space of amorphous carbon black [22]. However, little research has been reported to construct hierarchical structure in SAPO-11 molecular sieve using hard template [23]. Herein, an approach to synthesize SAPO-11 molecular sieve with hierarchical structure (Meso-SAPO-11) using carbon nanoparticles as hard template is demonstrated. The effects of carbon template on the mesoporosity, crystallization, morphology and acidity properties of the resulting molecular sieve are examined with $\mathrm{N}_{2}$ adsorption/desorption isotherm, XRD, TEM, SEM and Py-FTIR. The catalytic performance of the as-synthesized Meso-SAPO-11 on $n$-dodecane hydroisomerization are investigated to evaluate the mesoporous effects on catalytic activity and products selectivity.

\section{Experimental}

Synthesis of hierarchical SAPO-11 and catalyst

Based on the preparation method of traditional SAPO-11, aluminum isopropoxide, phosphoric acid and acidic silica sol were chosen as aluminum source, silicon source and phosphorus source, respectively. In a typical synthesis of hierarchical SAPO-11, the precursors were dispersed into proper amount of distilled water in a certain order under vigorously stirring. The mixture of di- $n$-propylamine and di-iso-propylamine was then slowly added into the solution as microporous template (SDA). The $\mathrm{pH}$ value of the resultant gel was adjusted to 6.86 by sulfuric acid after sufficient stirring. Carbon nanoparticles, which act as hard template, were added under vigorous stirring. The gel was then transferred into a stainless steel autoclave lined with polytetrafluorethylene, and crystallized at $473 \mathrm{~K}$ for $24 \mathrm{~h}$. Finally, the products were washed, dried at $373 \mathrm{~K}$ for $12 \mathrm{~h}$ and calcined at $873 \mathrm{~K}$ for another $12 \mathrm{~h}$ to remove the template.

Carbon material templates used in the experiment are commonly used in industry, for instance, carbon black (Degussa Company, FW200, denoted as FW200), conductive carbon black (Carbot Company, XC72R, denoted as Carbot), carbon nanotubes (denoted as CNTS) and graphitic carbon (denoted as Graphite).

Bifunctional Pt/meso-SAPO-11 catalyst was prepared by incipient-wetness impregnation method. Chloroplatinic acid solution, as a source of platinum, was prepared according to $0.5 \mathrm{wt} \% \mathrm{Pt}$ loading amount. Then, chloroplatinic acid solution was added into the pretableted mesoSAPO-11 in 20-40 mesh. The as-prepared meso-SAPO-11 with Pt precursor was deposited for $2 \mathrm{~h}$. Finally, the products were dried at $373 \mathrm{~K}$ for $2 \mathrm{~h}$ and calcined at $753 \mathrm{~K}$ for another $4 \mathrm{~h}$ to transform into the final bifunctional $\mathrm{Pt} /$ meso-SAPO-11 catalyst.

\section{Characterization methods}

The crystallinity of the prepared SAPO- 11 were analyzed by XRD, which was carried out on X'Pert PRO MPD (Netherlands, $\mathrm{Cu}$ target, $\mathrm{K} \alpha$ radiation $\lambda=0.1542 \mathrm{~nm}, 35 \mathrm{kV}$, $40 \mathrm{~mA}$ ), using molecular sieve phase analysis method, scan angle of $5^{\circ}-45^{\circ}$. The pore structure and morphology of molecular sieves were characterized by TEM, which was carried out on JEOL-2010 with acceleration voltage of $200 \mathrm{kV}$. The particle morphology and particle size of the samples were observed by SEM, which was carried out on S-4800 (Hitachi Company, acceleration voltage of $0.5-20 \mathrm{kV}$ ). $\mathrm{N}_{2}$ adsorption/desorption isotherms were recorded at $77 \mathrm{~K}$ with a Micromeritics TriStar 3000. The total surface area of the samples was calculated by BET method, the mesopore surface area and pore volume were calculated by $\mathrm{BJH}$ method based on the $\mathrm{N}_{2}$ desorption branch, and specific surface area of micropores was determined by substraction of total specific surface area from mesoporous one. The surface acidity analyses were carried out on a NEXUS FTIR (Thermo Fisher Scientific Company).

\section{Catalytic evaluation}

$\mathrm{N}$-dodecane hydroisomerization was conducted in a continuously flowing tubular fixed-bed micro-reactor at ambient pressure with $1.2 \mathrm{~g}$ catalyst loading. The catalyst 
was activated in situ in an $\mathrm{H}_{2}$ flow at $673 \mathrm{~K}$ for $4 \mathrm{~h}$ prior to reaction. The reaction temperature was $603 \mathrm{~K}$ at the WHSV feeding condition of $1.5 \mathrm{~h}^{-1}$ with $\mathrm{H}_{2} / \mathrm{n}$-dodecane molar ratio of 25 . Products were analyzed on-line by a Agilent 7820A GC (HP-PONA capillary column size of $50 \mathrm{~m} \times 0.2 \mathrm{~mm}$, FID detector). The reaction conversion, selectivity and yield were calculated by the program of GC.

\section{Results and discussion}

Short survey on carbon template

Based on the typical preparation method of traditional SAPO-11, hierarchical SAPO-11 molecular sieves were synthesized using different kinds of commercially provided carbon materials as hard template. The amount of carbon templates was determined by $5 \mathrm{wt} \%$ weight ratios of those to theoretical yield of SAPO-11. $\mathrm{N}_{2}$ adsorption/desorption isotherms of the meso-SAPO-11s prepared with four kinds of carbon materials were measured to examine the morphology effects of carbon templates, which are presented as Fig. 1. The calculation results based on measurement are listed in Table 1.

According to $\mathrm{N}_{2}$ adsorption/desorption isotherms of meso-SAPO-11, all the meso-SAPO-11 samples present type-IV isotherm and $\mathrm{H} 3$ hysteresis loop according to the IUPAC classification, which indicate that samples have the characteristics of both microporosity and mesoporosity. According to the pore size distribution of meso-SAPO-11 by different carbon templates, all the samples possess abundant of mesopores concentrated at $10-30 \mathrm{~nm}$. The pore size at $3.8 \mathrm{~nm}$ is artifact because of the Tensile Strength Effect for a forced closure of the H3 hysteresis loop [24] The hierarchical structure of as-synthesized

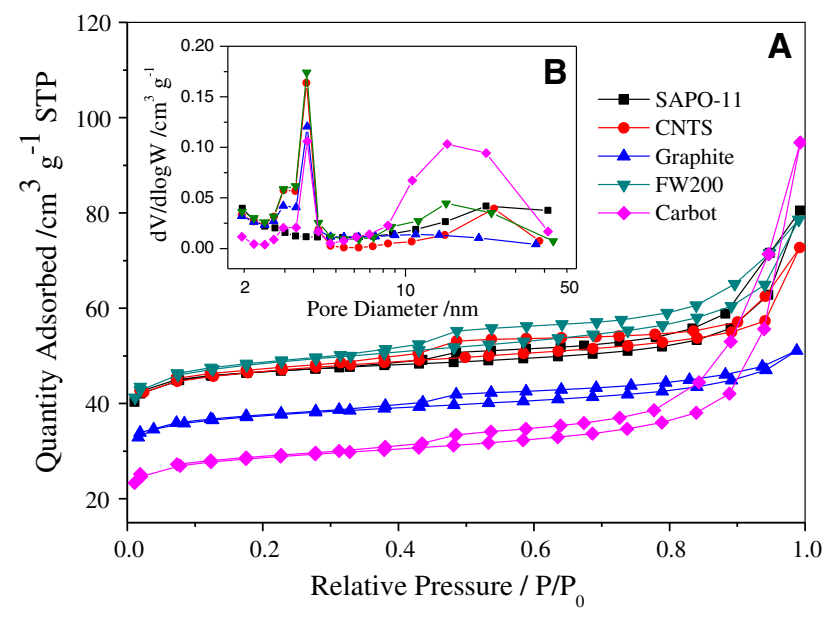

Fig. $1 \mathrm{~N}_{2}$ adsorption/desorption isotherms $(A)$ and pore size distribution $(B)$ of meso-SAPO-11 by different carbon templates
Table 1 Pore structure properties of meso-SAPO-11 by different carbon templates

\begin{tabular}{llrlll}
\hline $\begin{array}{l}\text { Carbon } \\
\text { template }\end{array}$ & $\begin{array}{l}\mathrm{A}_{\mathrm{BET}} / \\
\mathrm{m}^{2} / \mathrm{g}\end{array}$ & $\begin{array}{l}\mathrm{A}_{\text {micro/ }} \\
\mathrm{m}^{2} / \mathrm{g}\end{array}$ & $\begin{array}{l}\mathrm{A}_{\text {meso/ }} \\
\mathrm{m}^{2} / \mathrm{g}\end{array}$ & $\begin{array}{l}\mathrm{V}_{\text {total }} / \\
\mathrm{m}^{3} / \mathrm{g}\end{array}$ & $\begin{array}{l}\mathrm{V}_{\text {meso }} / \\
\mathrm{m}^{3} / \mathrm{g}\end{array}$ \\
\hline SAPO-11 & 142.89 & 116.32 & 26.57 & 0.127 & 0.065 \\
CNTS & 144.32 & 112.03 & 32.29 & 0.112 & 0.054 \\
Graphite & 124.86 & 98.49 & 26.37 & 0.079 & 0.033 \\
Carbot & 149.86 & 111.17 & 38.69 & 0.121 & 0.064 \\
FW200 & 130.04 & 87.54 & 42.50 & 0.136 & 0.088 \\
\hline
\end{tabular}

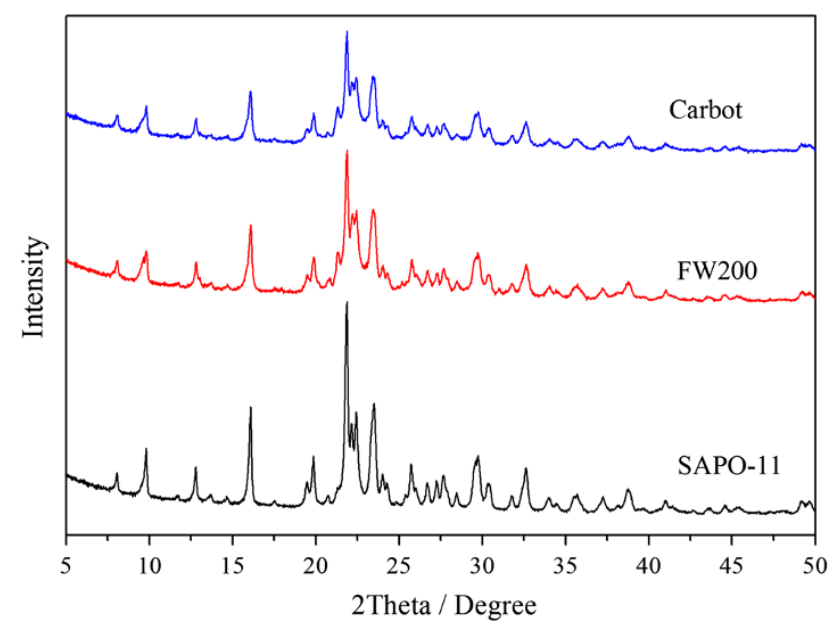

Fig. 2 XRD pattern of meso-SAPO-11 templated by Carbot carbon black

SAPO-11 is more remarkable when taking Carbot as hard template. $\mathrm{N}_{2}$ adsorption/desorption isotherm of the sample rises most significantly at high relative pressure $\mathrm{P} / \mathrm{P}_{0}$, and the jump segment of its hysteresis loop is the steepest. Correspondingly, the result of Table 1 shows that both the mesoporous specific surface area and pore volume of the meso-SAPO-11 templated by Carbot are relatively the largest, indicating a large content of mesopore.

XRD patterns of traditional SAPO-11 and meso-SAPO11 templated by Carbot and FW200 are presented in Fig. 2 . From the patterns, characteristic peaks at $2 \theta=8.09,9.84$, $12.78,16.10,19.98,21.93,22.26,22.49,23.48$, attributing to the typical SAPO-11 phase with AEL structures [25], could be detected. Moreover, the position and intensity of the peaks are identical to those reported for SAPO-11 without any additional diffraction peaks, indicating no significant effect of the carbon template on SAPO-11 hydrothermal crystallization.

Effects of template content

XRD patterns of meso-SAPO-11 templated by different contents of FW200 and Carbot are presented as Fig. 3. The 
number after abbreviation indicates the weight ratio of carbon template to theoretical yield of SAPO-11. All of the samples are highly crystallized and show well-resolved characteristic peaks for AEL structure, which indicate that the crystal structure can be properly preserved with the addition of carbon nanoparticles along the crystallization process, especially for the samples with content of $10 \mathrm{wt} \%$ FW200 and $15 \%$ Carbot.

The $\mathrm{N}_{2}$ sorption isotherms and pore size distribution of meso-SAPO-11 by different contents of FW200 and Carbot templates are presented in Figs. 4 and 5, respectively. As we can see from Figs. $4 \mathrm{a}$ and 5a, type IV adsorption/ desorption isotherms and $\mathrm{H} 3$ hysteresis loop for typical hierarchical structure of material are observed for all the samples. High initial uptakes at low relative pressure are followed by nearly horizontal adsorption and desorption branches. The upward turn with a hysteresis loop is indicative of the mesoporosity, which is obviously generated form the carbon template introduction. The $\mathrm{N}_{2}$ adsorption/desorption isotherms of meso-SAPO-11

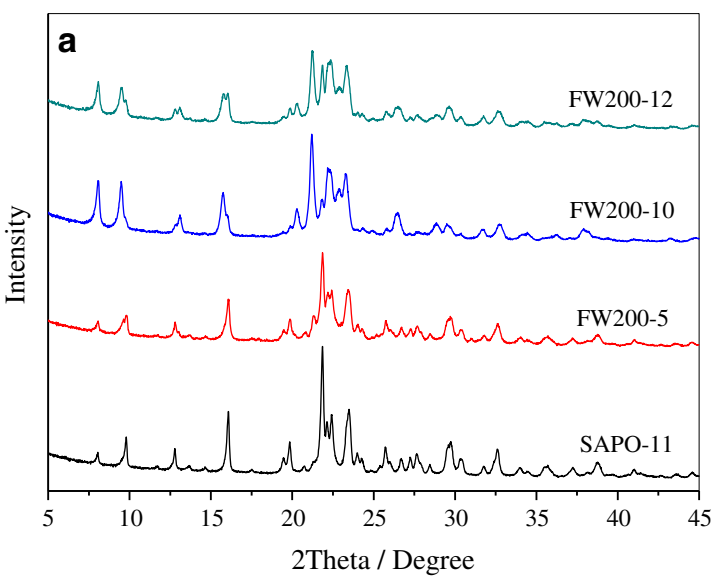

templated by Carbot rising more significantly at high relative pressure $\mathrm{P} / \mathrm{P}_{0}$, and the jump segment of its hysteresis loop being steeper. According to the pore size distribution of meso-SAPO-11 in Figs. 4b and 5b, the meso-SAPO-11 by FW200 template possesses a concentrated distribution in about $12 \mathrm{~nm}$, while the meso-SAPO- 11 by Carbot template possesses a concentrated distribution in about $25 \mathrm{~nm}$, which is in line with the parent template diameter $(12 \mathrm{~nm}$ for Degussa FW200 and $25 \mathrm{~nm}$ for Carbot $\mathrm{XC72R}$ ).

The results of $\mathrm{N}_{2}$ adsorption/desorption isotherms of meso-SAPO-11 by different contents of FW200 and Carbot templates are listed in Tables 2 and 3. According to the results, the mesoporous specific surface area and pore volume increase with the increase of the amount of the carbon templates, which indicate that more carbon templates introduction could construct more mesopores. However, the samples prepared with excessive FW200 show a poorer nature of mesoporosity. When further increasing carbon content from 10 to $15 \mathrm{wt} \%$, both the

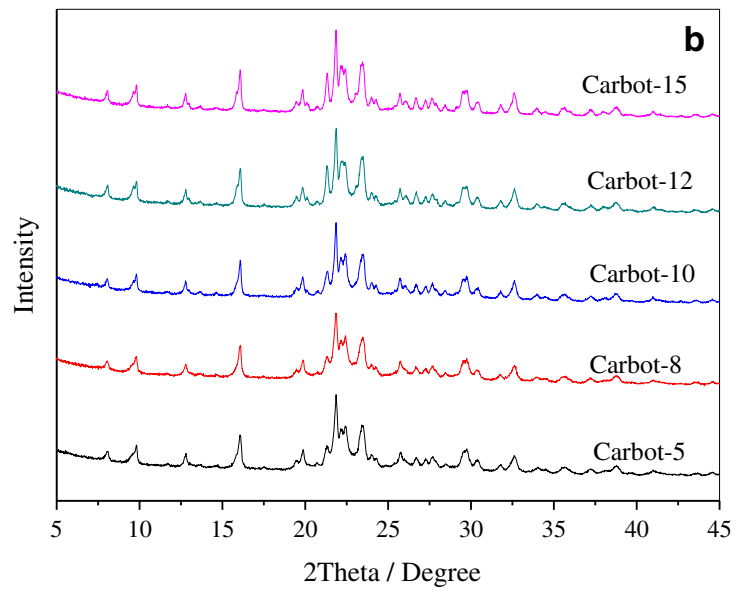

Fig. 3 XRD pattern of meso-SAPO-11 templated by FW200 carbon black (a) and Carbot carbon black (b)
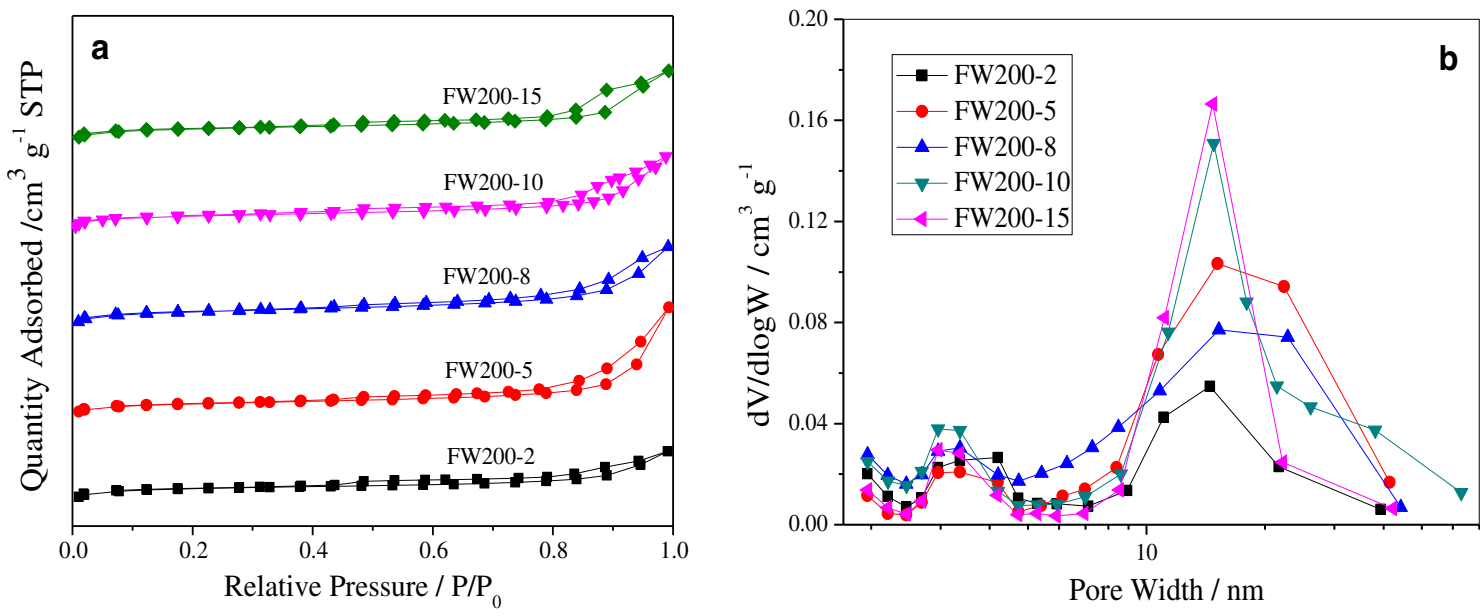

Fig. $4 \mathrm{~N}_{2}$ sorption isotherms (a) and pore size distribution (b) of meso-SAPO-11 by different FW200 content 

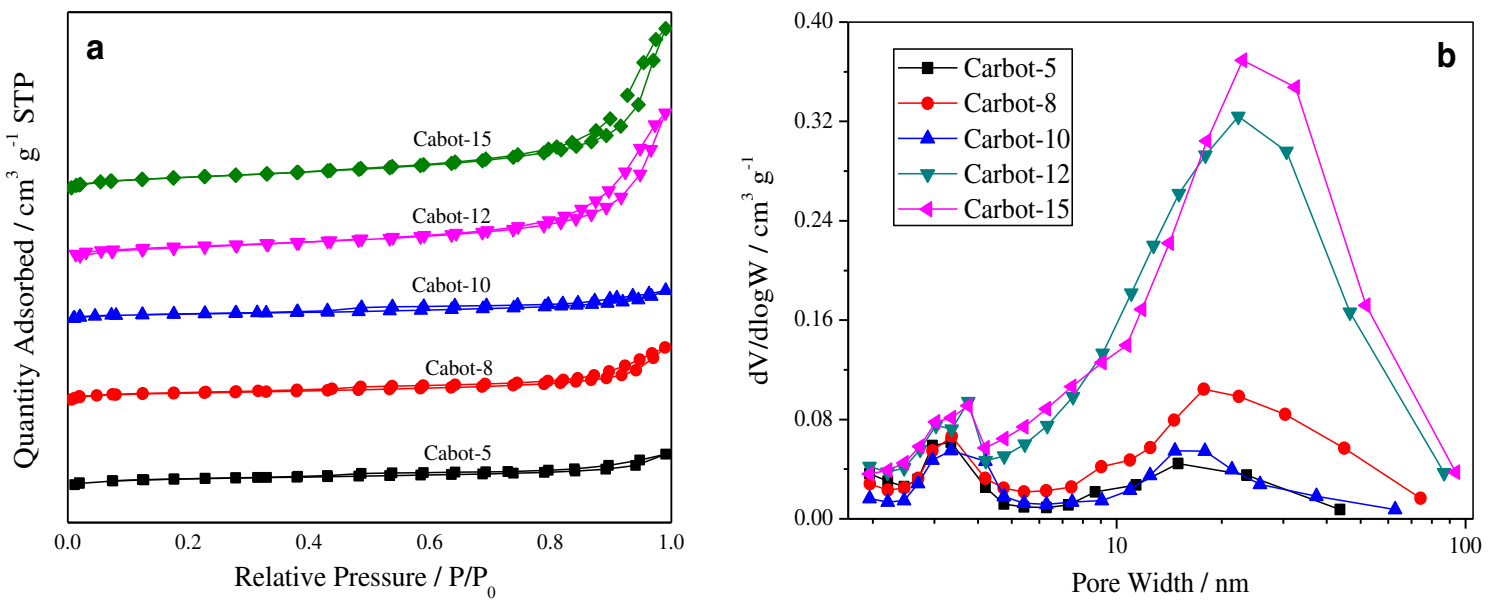

Fig. $5 \mathrm{~N}_{2}$ sorption isotherms (a) and pore size distribution (b) of meso-SAPO-11 by different Carbot content

specific surface area and mesopore volume decrease. An optimal amount for FW200 as hard template is obtained, which is said to be $10 \%$ in weight. This result could be explained that excessive carbon template constructs excessive multi-mesopores and possess poor thermal stability, leading to mesopore collapse during thermal treatment. The comprehensive consideration of the surface area and pore structure results indicate that the meso-SAPO-11 templated by $10 \mathrm{wt} \%$ FW200 and $15 \mathrm{wt} \%$ Carbot show a relatively better mesopore structure.

Table 2 Pore structure properties of meso-SAPO-11 by different FW200 content

\begin{tabular}{llllll}
\hline Samples & $\begin{array}{l}\mathrm{A}_{\mathrm{BET}} / \mathrm{m}^{2} / \\
\mathrm{g}\end{array}$ & $\begin{array}{l}\mathrm{A}_{\text {micro }} / \mathrm{m}^{2} / \\
\mathrm{g}\end{array}$ & $\begin{array}{l}\mathrm{A}_{\text {meso }} / \mathrm{m}^{2} / \\
\mathrm{g}\end{array}$ & $\begin{array}{l}\mathrm{V}_{\text {total }} / \mathrm{m}^{3} / \\
\mathrm{g}\end{array}$ & $\begin{array}{l}\mathrm{V}_{\text {meso }} / \mathrm{m}^{3} / \\
\mathrm{g}\end{array}$ \\
\hline SAPO-11 & 142.89 & 116.32 & 26.57 & 0.127 & 0.065 \\
FW200-2 & 133.88 & 94.06 & 39.82 & 0.137 & 0.086 \\
FW200-5 & 130.04 & 87.54 & 42.50 & 0.136 & 0.088 \\
FW200-8 & 127.25 & 83.78 & 43.47 & 0.153 & 0.106 \\
FW200- & 111.15 & 70.57 & 40.58 & 0.171 & 0.132 \\
10 & & & & & \\
FW200- & 99.09 & 64.17 & 34.92 & 0.147 & 0.115 \\
15 & & & & & \\
\hline
\end{tabular}

Table 3 Pore structure properties of meso-SAPO-11 by different Carbot content

\begin{tabular}{|c|c|c|c|c|c|}
\hline Samples & $\begin{array}{l}\mathrm{A}_{\mathrm{BET}} / \mathrm{m}^{2} / \\
\mathrm{g}\end{array}$ & $\begin{array}{l}\mathrm{A}_{\text {micro } /} \mathrm{m}^{2} / \\
\mathrm{g}\end{array}$ & $\begin{array}{l}\mathrm{A}_{\text {meso } /} \mathrm{m}^{2} / \\
\mathrm{g}\end{array}$ & $\begin{array}{l}\mathrm{V}_{\text {total }} / \mathrm{m}^{3} / \\
\mathrm{g}\end{array}$ & $\begin{array}{l}\mathrm{V}_{\text {meso }} / \mathrm{m}^{3} / \\
\mathrm{g}\end{array}$ \\
\hline SAPO-11 & 142.89 & 116.32 & 26.57 & 0.127 & 0.065 \\
\hline Carbot-5 & 149.86 & 111.17 & 38.69 & 0.122 & 0.064 \\
\hline Carbot-8 & 111.02 & 66.86 & 44.16 & 0.138 & 0.105 \\
\hline Carbot-10 & 125.38 & 79.38 & 46 & 0.159 & 0.119 \\
\hline Carbot-12 & 110.11 & 21.66 & 88.45 & 0.303 & 0.297 \\
\hline Carbot-15 & 126.3 & 32.37 & 93.93 & 0.339 & 0.326 \\
\hline
\end{tabular}

In situ Py-FTIR spectroscopy of meso-SAPO-11 templated by FW-200 and Carbot is presented in Fig. 6. From the figures, all the spectra of pyridine adsorbed on mesoSAPO-11 exhibit characteristic bands at 1,548 and $1,448 \mathrm{~cm}^{-1}$, which are attributed to Brønsted acid sites (B acid) and Lewis acid sites (L acid), respectively. For both two groups of samples, the amount of B acid increases with the increase of the content of the carbon templates, while the amount of L acid decreases. Meso-SAPO-11 s prepared from template contents of $10 \% \mathrm{wt}$ FW200 and $15 \% \mathrm{wt}$ Carbot possess the highest proportion of $\mathrm{B}$ acid and $\mathrm{L}$ acid.

SEM and TEM images of traditional and hierachical SAPO-11 by the two kinds of carbon templates are shown in Fig. 7, and the original carbon templates are shown as insert images as well. According to the images, it can be seen that the surface of traditional SAPO-11 crystals is relatively complete and plane with no mesostructure presented, while the surface of the mesoSAPO-11 crystals is chipped and rough, especially for the meso-SAPO-11 templated by Carbot. The diameter of the mesopore is approximately $10-20 \mathrm{~nm}$ as indicated in white cycle of the images, which is in accordance with the results shown in the Figs. 4 and 5. The images of original carbon templates are also presented as insert images, which showed a worm shape. It could be found that the morphologies of carbon templates are different to the resulting meso-SAPO-11, and the role of carbon black as template during the crystallization needs further investigation.

\section{Catalytic evaluation of meso-SAPO-11}

The n-dodecane hydroisomerization evaluation of the catalysts prepared by loading $0.5 \mathrm{wt} \% \mathrm{Pt}$ on above-mentioned meso-SAPO-11 samples are showed in Tables 4 and 5. From the results of Table 4, the cracking selectivity 

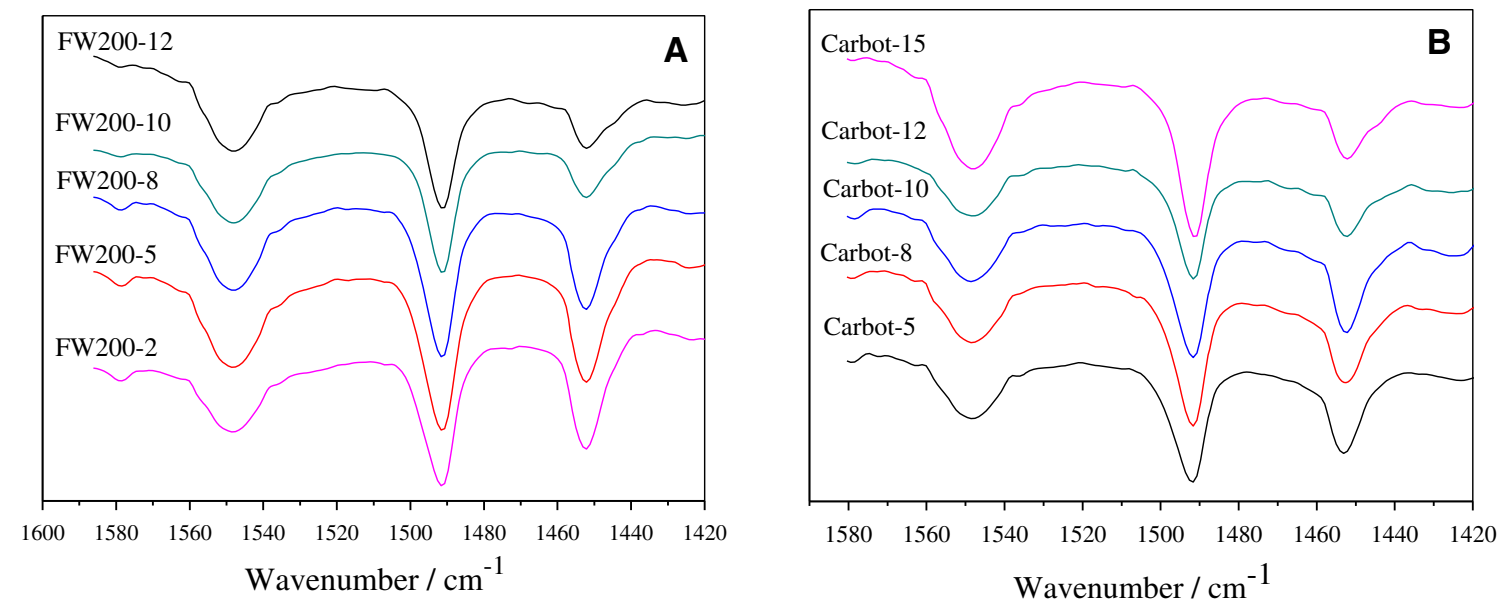

Fig. 6 In situ Py-FTIR spectroscopy of meso-SAPO-11 by FW-200 carbon template (a) and Carbot carbon template (b)
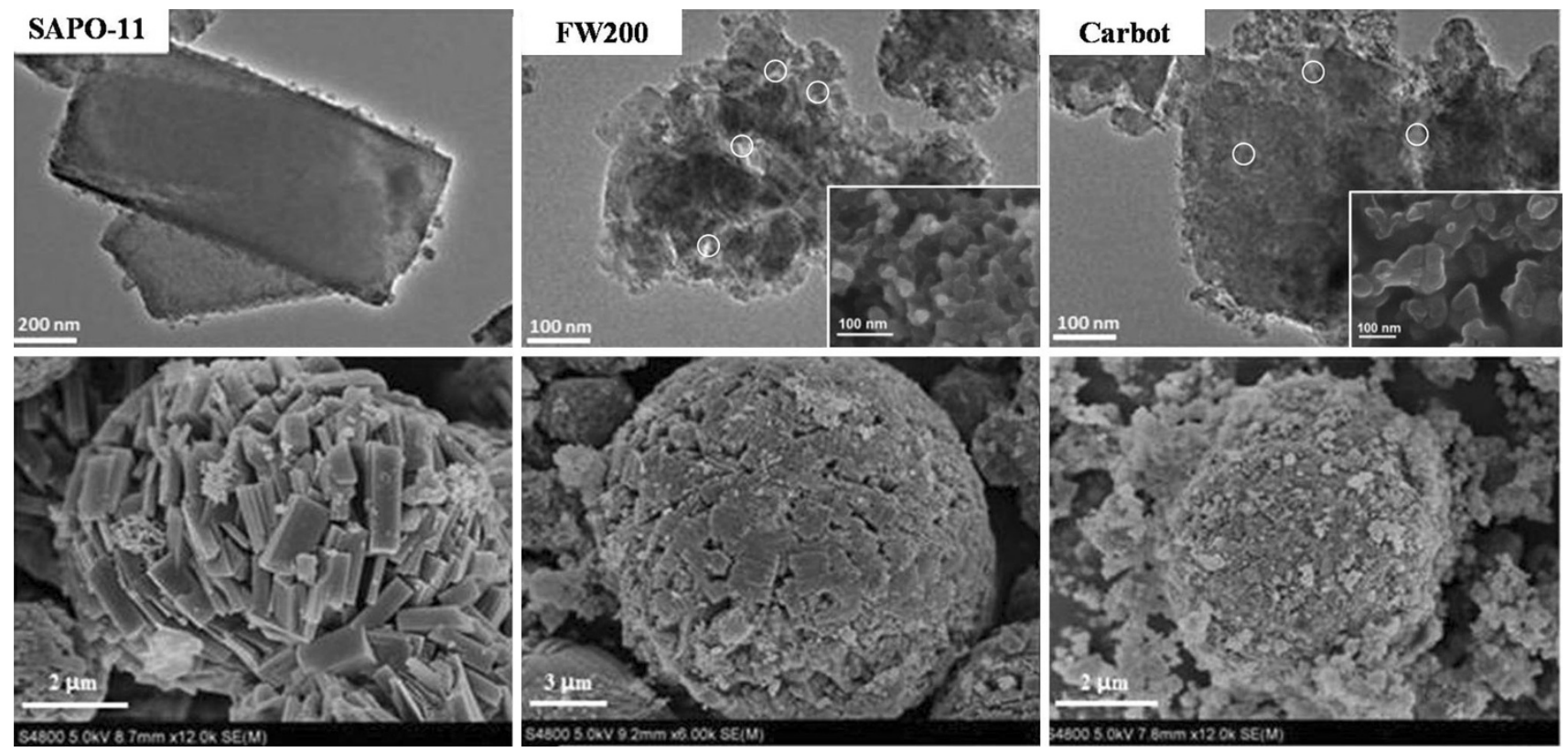

Fig. 7 SEM and TEM images of meso-SAPO-11 templated by different carbon black, insert images are corresponding carbon templates

decreases at first and then increases with the increase of FW200 content, while the isomer yield increases at first and then decreases with the multibranched selectivity. The isomer yield and the multibranched selectivity reach the highest value by the content of $10 \mathrm{wt} \%$ FW200, while the cracking selectivity decreases to the least. It could be explained from the results that more mesopores are constructed with the increase of the content of FW200 in a certain range. However, the samples with excessive FW200 carbon templates show a poorer nature of mesopore, which indicates excessive carbon templates construct excessive multi-mesopores with poor thermal stability, leading to the collapse of the mesopores, even to block the original micropores. According to the results of Table 5, the conversion and cracking selectivity decrease while the isomer selectivity and isomer yield increase with the increase of Carbot templates content. It also can be seen that the catalytic performances of meso-SAPO-11 prepared higher than $5 \mathrm{wt} \%$ are better than traditional SAPO-11 as support. The results could be explained by the decrease of the crystallinity of the molecular sieves. The multibranched selectivity increases with the increase of the content of the Carbot templates, indicating that more multibranched isomerization reaction occurred in the mesopores due to the low restriction to micropores and more exposition of microporous mouth. 
Table 4 Isomerization evaluation of meso-SAPO-11 templated by different FW200 content

\begin{tabular}{llllll}
\hline Catalyst & Conversion/\% & Selectivity/\% & & Isomer yield/\% \\
\cline { 3 - 6 } & & Cracking & Monobranched & Multibranched \\
\hline FW-2 & 97.84 & 58.95 & 19.15 & 21.89 & 40.16 \\
FW-5 & 97.75 & 51.27 & 21.67 & 27.05 & 47.63 \\
FW-8 & 97.76 & 50.33 & 22.39 & 27.28 & 48.55 \\
FW-10 & 95.18 & 30.74 & 41.38 & 27.88 & 65.92 \\
FW-12 & 97.27 & 52.85 & 23.54 & 23.61 & 45.86 \\
\hline
\end{tabular}

Table 5 Isomerization evaluation of meso-SAPO-11 templated by different Carbot content

\begin{tabular}{llllll}
\hline Catalyst & Conversion/\% & \multicolumn{2}{l}{ Selectivity/\% } & & Isomer yield/\% \\
\cline { 3 - 6 } & & Cracking & Monobranched & Multibranched \\
\hline Carbot-5 & 97.17 & 41.47 & 25.62 & 32.91 & 56.87 \\
Carbot-8 & 96.90 & 37.28 & 28.75 & 33.97 & 60.77 \\
Carbot-10 & 95.14 & 29.91 & 38.52 & 31.57 & 66.68 \\
Carbot-12 & 94.30 & 24.82 & 42.20 & 32.97 & 70.89 \\
Carbot-15 & 94.22 & 14.18 & 49.59 & 36.13 & 80.86 \\
SAPO-11 & 91.10 & 33.86 & 36.41 & 29.73 & 60.25 \\
\hline
\end{tabular}

\section{Conclusion}

The SAPO-11 with hierarchical structure (Meso-SAPO-11) was successfully prepared with the aid of carbon materials as hard template. Compared with the traditional SAPO-11, both the mesoporous specific surface area and volume of meso-SAPO-11 were increased significantly, while the crystal structure was properly preserved. After brief survey on different kinds of carbon materials, it was found that both FW200 and Carbot nanoparticles could be used to generate hierarchical structure effectively, by which $10 \mathrm{wt} \%$ FW200 and $15 \mathrm{wt} \%$ Carbot showed the best nature of mesoporosity. The increase of mesoporosity could significantly improve the hydroisomerization performance. Correspondingly, the meso-SAPO- 11 by $10 \mathrm{wt} \%$ FW200 and $15 \mathrm{wt} \%$ Carbot showed the best performance on $\mathrm{n}$-dodecane isomer product yield.

Acknowledgments This work was supported by Science and Technology Development Project of CNPC (No. 11-13-01-05); National Science Foundation China (U1362202 and 21206196), Innovation Foundation of CNPC (2013D-5006-0404), and Funds for Distinguished Young Scientists of Shandong Province (BS2012NJ013).

Open Access This article is distributed under the terms of the Creative Commons Attribution License which permits any use, distribution, and reproduction in any medium, provided the original author(s) and the source are credited.

\section{References}

1. Kobayashi M, Saitoh M, Togawa S, Ishida K (2008) Branching structure of diesel and lubricant base oils prepared by isomerization/hydrocracking of fischer-tropsch waxes and $\alpha$-olefins. Energy Fuels 23:513-518

2. Lin L (1964) Isomerization of n-alkanes. In Research Report Bulletin of Institute of Chemical Physics, Chinese Academy of Sciences. Beijing Science \& Technology Press

3. Calemma V, Peratello S, Perego C (2000) Hydroisomerization and hydrocracking of long-chain $n$-alkanes on Pt/amorphous $\mathrm{SiO}_{2}-\mathrm{Al}_{2} \mathrm{O}_{3}$ catalysts. Appl Catal A 190:207-218

4. Blomsma E, Martens JA, Jacobs PA (1997) Hydroisomerization and hydrocracking of heptane over bimetallic bifunctional Pt-Pd/ H-Beta and Pt-Pd/USY zeolite catalysts. J Catal 165:241-248

5. Martens JA, Parton R, Uytterhoeven L, Jacobs PA (1991) Selective conversion of decane into branched isomers : a comparison of platinum/ZSM-22, platium/ZSM-5 and platium/USY zeolite catalysts. Appl Catal A 76:95-116

6. Souverijns W, Martens JA, Froment GF, Jacobs PA (1998) Hydrocracking of isoheptadecanes on $\mathrm{Pt} / \mathrm{H}-\mathrm{ZSM}-22$ : a example of pore-mouth catalysis. J Catal 174:177-184

7. Miller SJ (1992) Wax isomerization using catalyst of specific pore geometry. US. Patent. 5135638, Chevron Res \& Tech 1992-08-04

8. Meriaudeau P, Tuan VA, Lefebvre F, Nghiem VT, Naccache C (1998) Synthesis and characterization of SAPO-41:effect of silicon content and the crystal size on the hydroisomerization of $n$ octane over Pt-Pd/SAPO-41. Microporous Mesoporous Mater 26:161-173

9. Sinha AK, Sivasanker S, Ratnasamy P (1998) Hydroisomerization of n-alkanes over Pt/SAPO-11 and SAPO-31 synthesized from aqueous and nonaqueous media. Ind Eng Chem Res $37: 2208-2214$ 
10. Mériaudeau P, Tuan VuA, Nghiem VuT, Sapaly G, Naccache C (1999) Comparative evaluation of the catalytic properties of SAPO-11 and ZSM-48 for hydroisomerization of octane: effect of the acidity. J Catal 185:435-444

11. Taylor RJ, Petty RH (1994) Selective hydroisomerization of long chain normal paraffins. Appl Catal A 119:121-138

12. Park KC, Ihm SK (2000) Comparison of Pt/zeolite catalysts for n-hexadecane hydroisomerization. Appl Catal A 203:201-209

13. Girgis MJ, Tsao YP (1996) Impact of catalyst metal-acid balance in $n$-hexadecane hydroisomerization and hydrocracking. Ind Eng Chem Res 35:386-396

14. Corma A, Palomares A, Mrquez F (1997) Determining the nature of the active sites of $\mathrm{Cu}$-beta zeolites for the selective catalytic reduction (SCR) of $\mathrm{NO}_{\mathrm{x}}$ by using a coupled reaction-XAES/XPS study. J Catal 170:132-139

15. Miller SJ (1994) New molecular sieve process for lube dewaxing by wax isomerization. Microporous Mater 2:439-449

16. Lopez-Orozco S, Inayat A, Schwab A, Selvam T, Schwieger W (2011) Zeolitic materials with hierarchical porous structures. Adv Mater 23:2602-2615

17. Yang X, Lu T, Chen C, Zhou LP, Wang F, Su YL, Xu J (2011) Synthesis of hierarchical AlPO-n molecular sieves templated by saccharides. Microporous Mesoporous Mater 144:176-182

18. Fan Y, Xiao H, Shi G, Liu H, Bao XJ (2012) Alkylphosphonic acid- and small amine-templated synthesis of hierarchical silicoaluminophosphate molecular sieves with high isomerization selectivity to di-branched paraffins. J Catal 285:251-259

19. Egeblad K, Christensen CH, Kustova M, Christensen CH (2007) Templating mesoporous zeolites. Chem Mater 20:946-960

20. Yang XY, Li Y, Lemaire A, Yu JG, Su BL (2009) Hierarchically structured functional materials: synthesis strategies for multimodal porous networks. Pure Appl Chem 81:2265-2307

21. Holland BT, Abrams L, Stein A (1999) Dual templating of macroporous silicates with zeolitic microporous frameworks. J Am Chem Soc 121:4308-4309

22. Madsen C, Jacobsen CJH (1999) Nanosized zeolite crystalsconvenient control of crystal size distribution by confined space synthesis. Chem Commun 673-674

23. Liang J, Wang FP (2011) Synthesis and characterization of mesoporous SAPO-11 by using carbon particles. Adv Mater Res 306:1576-1579

24. Groen JC, Peffer LAA, Pérez Ramírez J (2003) Pore size determination in modified micro- and mesoporous materials. Pitfalls and limitations in gas adsorption data analysis. Microporous Mesoporous Mater 60:1-17

25. Wilson ST, Lok BM, Messina CA, Cannan TR, Flanigen EM (1982) Aluminophosphate molecular sieves: a new class of microporous crystalline inorganic solids. J Am Chem Soc 104:1146-1147 